\section{History of science is good for you}

\section{Mathias Grote and Maureen A. O'Malley}

We note with considerable interest the recent editorial in Nature Reviews Microbiology (Raiders of the lost articles. Nature Rev. Microbiol. 8, 610 (2010)) $)^{1}$. The article raises a tremendously important issue - namely the relevance of science's past for its present productivity - but in our opinion it narrows the problem to one of accessing publications in the digital age. Most strikingly, the argument omits an entire profession whose business it is to comb through the archives of the past: historians of science.

We think, therefore, that there are additional sides to the problem that require additional responses. First, the editorial assumes that locating publications has become more difficult in recent times. For many journals, the contrary is the case. Their contents have been digitalized as far back as the journal's founding dates, thus allowing readers access to original papers such as Antonie van Leeuwenhoek's first report of 'animalcules' in 1674 (REF. 2). Despite access restrictions to some journals, these archives of online material greatly facilitate historical research and allow such material to be integrated into scientific practice.

Second, as the editorial notes, 'data deluges' can obscure exploration of the past owing to limited search tools, insufficient indexing of historical articles and omission of abstracts. A much bigger problem, however, is that historical material is often structured differently from present publications. Even 50 years ago, many scientific articles did not even have abstracts. Keyword searches, another issue raised in the editorial, might miss important contributions, as scientific publishing of past times was a multilingual affair. And to make things more complex altogether, scientific concepts change over time. A researcher interested in the history of plasmid research, for example, will discover that today's F-factor of Escherichia coli was called an 'episome' in the $1960 \mathrm{~s}^{3-5}$, and an exclusive search for 'plasmid' will skew the data set of historical papers.

To access science's past, therefore, one needs not only raw documents but also, most importantly, an understanding of the history of science, including the changes in disciplines, techniques and concepts. Such an understanding cannot be provided by digital tools, but it could result from cooperation between scientists and historians of science. Furthermore, the editorial ignores historical books and articles written by microbiologists, in which deep and extensive analyses of historical material are carried out. Texts by Clifford Dobell ${ }^{6}$, William Bulloch $^{7}$, Thomas Brock ${ }^{8}$, and Howard Gest ${ }^{9}$ are just some of the examples of this genre of bibliographically rich literature. The writers have compiled, translated and interpreted historical texts and often managed to provide some of the historical context in which such material must be understood.

The editorial concludes by encouraging microbiologists to engage more extensively with historical literature. As humanities scholars, we fully support this manifesto and propose two additional strategies for achieving this goal. First, history (and philosophy) of science should become an integral part of life science curricula in order to make students aware of the past and to give them the proper tools to access it. Second, scientific journals, such as Nature Reviews Microbiology, should encourage more historical reviews, whether they are written by microbiologists or by historians (and ideally, sometimes, by collaborations of both). Both these approaches, however, cannot presume that history is there for the taking. As in any scientific interpretation, historical understanding has many levels.

Mathias Grote and Maureen A. O'Malley are at Egenis, University of Exeter, Exeter EX4 4PJ, UK Correspondence to M.G. e-mail:M.Grote@exeter.ac.uk

1. [No authors listed]. Raiders of the lost articles. Nature Rev. Microbiol. 8, 610 (2010).

2. van Leeuwenhoek, A. Concerning little animals by him observed in rain- well- sea- and snow-water; as also in water wherein pepper had lain infused. Philos. Trans. 12, 821-831 (1676).

3. Grote, M. Hybridizing bacteria, crossing methods, cross-checking arguments: the transition from episomes to plasmids (1961-1969). Hist. Philos. Life Sci. 30, 407-430 (2008).

4. Lederberg, J. Plasmid (1952-1997). Plasmid 39, 1-9 (1998).

5. Morange, M. What history tells us XIX. The notion of the episome. J. Biosci. 34, 845-848 (2009).

6. Dobell, C. Antony van Leeuwenhoek and his 'Little Animals': Being Some Account of the Father of Protozoology and Bacteriology and his Multifarious Discoveries in these Disciplines (Hardcourt, Brace and Co., New York, 1932).

7. Bulloch, W. The History of Bacteriology (Oxford Univ. Press, Oxford, 1938).

8. Brock, T. D. (ed.) Milestones in Microbiology (Prentice Hall, Upper Saddle River, New Jersey, 1961).

9. Gest, H. The discovery of microorganisms by Robert Hooke and Antoni Van Leeuwenhoek, Fellows of the Royal Society. Notes Rec. Roy. Soc. 58, 187-201 (2004).

CFI statement

The authors declare no competing financial interests. 